\title{
Identification of Helicobacter pylori DNA in the mouths and stomachs of patients with gastritis using PCR
}

\author{
N P Mapstone, D A F Lynch, F A Lewis, A T R Axon, D S Tompkins, M F Dixon, \\ P Quirke
}

\begin{abstract}
Aims-To determine the prevalence of Helicobacter pylori colonisation in the mouths of patients with $\mathrm{H}$ pylori gastritis.

Methods-A nested polymerase chain reaction test for the $16 S$ ribosomal RNA gene of $H$ pylori was used on saliva, dental plaque, gastric juice and gastric biopsy specimens from patients attending a dyspepsia clinic.

Results-Thirteen patients had histologically confirmed Helicobacter associated gastritis. Twelve of these had positive gastric aspirates by PCR. Five had at least one positive oral specimen. Eight patients with normal gastric biopsy specimens had no PCR positive oral specimens or gastric aspirates. All, however, had PCR positive gastric biopsy specimens. In an attempt to determine the origin of these positive results in normal patients, it was shown that biopsy forceps could contaminate specimens with DNA from previous patients.

Conclusion-The demonstration of the organism in the mouths of a substantial proportion of dyspeptic patients has major implications for the spread of $H$ pylori and identifies a potential source for reinfection following eradication of the organism from the stomach.
\end{abstract}

(f Clin Pathol 1993;46:540-543)

Academic Unit of Pathology, Chemical Pathology, and Immunology, The General Infirmary at Leeds, Leeds N P Mapstone F A Lewis M F Dixon P Quirke

Centre for Digestive Diseases, The General Infirmary at Leeds A T R Axon

D A F Lynch

Department of Microbiology, Bradford Royal Infirmary, Bradford D S Tompkins

Correspondence to: Dr N P Mapstone, Academic Unit of Pathology, Chemical Pathology and Immunology, Pathology and Immunology The General Infirmary at Leeds, Great Geor
Leeds, LS19 6BT

Accepted for publication 8 December 1992
Few data are available for the prevalence of Helicobacter pylori in the mouth. Information from conventional microbiological techniques varies. Majmudar et al, in a population of Indian patients, found a high prevalence with all 40 patients having positive oral specimens by culture and CLO test. ${ }^{1}$ Another study, using the CLO test as the only indicator of oral infection, suggested an oral prevalence of $98 \%$ in dyspeptic patients. This included a significant number of patients with no evidence of gastric infection. ${ }^{2}$ Krajden et al found a much lower prevalence, however, with only one of 71 patients having positive oral specimens by culture. ${ }^{3}$ If the organisms are present in the mouths of patients with gastritis it could be a reservoir for spread of the disease. It would also be a likely source of reinfection, accounting for recurrence of Helicobacter gastritis and associated duodenal disease in $35.3 \%$ of patients with duodenal ulcer in the year following eradication of infection. ${ }^{4}$
Several reports have appeared in which molecular techniques, specifically the polymerase chain reaction (PCR), have been used for the identification of $H$ pylori. ${ }^{5-9}$ We recently described a PCR test for the organism ${ }^{10}$ and sought to use it to clarify the prevalence of oral carriage of $H$ pylori.

\section{Methods}

Twenty three dyspeptic patients had saliva taken before and after citric acid stimulation. Dental plaque was collected with a sterile toothpick. The patients then underwent upper gastrointestinal endoscopic examination. Gastric juice was aspirated through a sterile Wilson Cook catheter. Two gastric antral biopsy specimens were taken, one submitted for histological examination (including a modified Giemsa stain), and one for PCR. Endoscopes were fully disinfected using an Auto Disinfector II (Olympus Keymed) before and after each examination.

All PCR specimens were immediately frozen in individual containers and underwent DNA extraction using a standard proteinase $\mathrm{K}$, hexadecyl-trimethyl-ammonium bromide (CTAB) and phenol chloroform method identical with that used in our initial work. ${ }^{10}$

Our PCR method differed from that used previously ${ }^{10}$ in that a nested PCR was used to enhance sensitivity. Previous experiments had shown that a single step PCR detected $H$ pylori in gastric specimens, but was not sensitive enough to show the presence of the organism in saliva.

Three primers were used; an initial 30 cycles with an annealing temperature of $55^{\circ} \mathrm{C}$ amplified a 446 base pair fragment of the gene encoding $H$ pylori $16 \mathrm{~S}$ rRNA. Two primers were used in this step-HP1 and HP3. A further 30 cycles with an annealing temperature of $62^{\circ} \mathrm{C}$ amplifying a 109 base pair fragment were then performed. This step used one primer from the initial reaction and another internal to the fragment amplified in that step (HP1 and HP2). The sequences of the primers (expressed 5' to 3') were as follows: HP1 (CTG GAG AGA CTA AGC CCT CC, position 834-853); HP2 (ATT ACT GAC GCT GAT TGT GC, position 744-763); and HP3 (AGG ATG AAG GTT TAA GGA TT, position 407-426).

Using this method as little as $10 \mathrm{fg}$ of bacterial DNA could be identified (corresponding to about 10 bacteria). The specificity was high, with no reaction to the most closely 


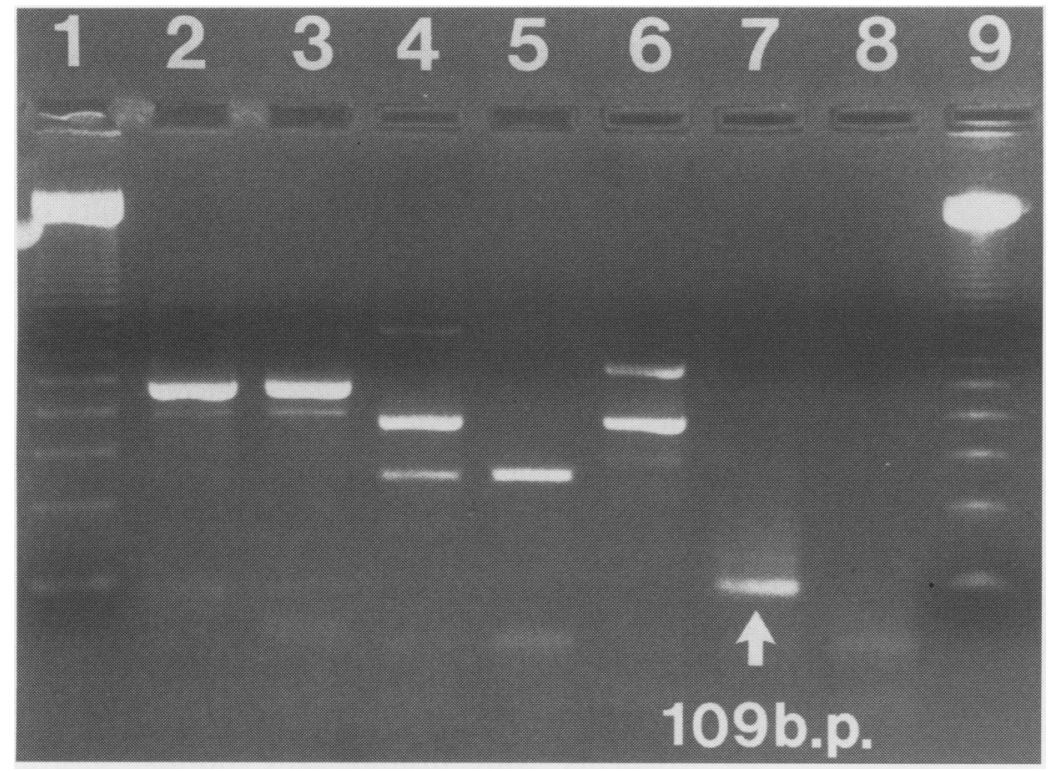

Figure 1 PCR gel showing specificity of the test. Lanes 1 and 9123 base pair ladder; lanes 2 and $30.1 \mu \mathrm{g} \mathrm{H}$ mustelae DNA; lane $40.1 \mu \mathrm{g} \mathrm{H}$ fennelliae DNA; lane $50.1 \mu \mathrm{g}$ $H$ cinaedi DNA; lane $60.1 \mu \mathrm{g}$ Wolinella succinogenes DNA; lane $70.01 \mathrm{pg} \mathrm{H}$ pylori $D N A$; lane 8 negative control. 109 base pairs is the specific amplification product of $H$ pylori DNA.
Figure 2 Southern Blot of specificity PCR shown in figure 1 , showing

hybridisation of probe with H pylori specimen alone. related non-Helicobacter Wolinella succinogenes, ${ }^{11}$ or the other Helicobacters known to be found in humans, $H$ fennelliae or $H$ cinaedi. There was a faint reaction when very large amounts of DNA from $H$ mustelae were used (fig 1). This faint reaction was seen with $1 \times 10^{-7} \mathrm{~g}$ of $H$ mustelae DNA. As little as $1 \times 10^{-14} \mathrm{~g} H$ pylori DNA was needed for a much stronger positive band. $H$ mustelae has been cultured in ferrets but not in humans. Non-specific bands of amplified DNA of varying sizes were sometimes present in the nested PCR. These bands were seen only when there was no $H$ pylori DNA in the specimen. They are probably due to non-specific amplified products from the increased number of cycles required to detect the very small numbers of bacteria.

Southern blots were performed on a selection of the PCR positive samples to confirm that the amplified product was from $H$ pylori. It was also done on the specificity experiments to exclude cross-reactions. The PCR products were transferred to a nitrocellulose membrane. A $\mathrm{P}^{32}$ labelled internal probe was used ( $p H P$, sequence 5' to 3' CAT CCA TCG TTT AGG GCG TG, position

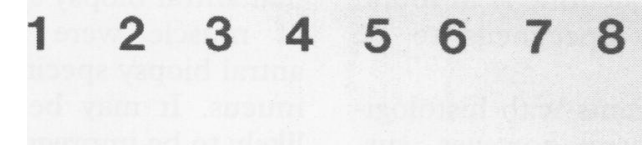

Histological and $P C R$ results

\begin{tabular}{lll}
\hline Sample & $\begin{array}{l}\text { Helicobacter positive } \\
\text { patients } \\
(n=13)\end{array}$ & $\begin{array}{l}\text { Histologically } \\
\text { normal } \\
\text { patients }(n=8)\end{array}$ \\
\hline Unstimulated saliva & 1/13 positive & $0 / 8$ positive \\
Stimulated saliva & 3/13 positive & $0 / 8$ positive \\
Tooth scrapings & 2/13 positive & $0 / 8$ positive \\
Gastric aspirates & 12/13 positive & 0/8 positive \\
Gastric biopsies & 12/13 positive & 8/8 positive \\
\hline
\end{tabular}

806-825) This was hybridised with the PCR products on the membrane overnight at $45^{\circ} \mathrm{C}$. Only the specific size band (109 base pairs) hybridised with the $H$ pylori specific oligonucleotide probe (fig 2).

Each patient's group of five specimens underwent DNA extraction in a single batch accompanied by a negative control tube containing only water, but subjected to all the same steps as the other specimens. This controlled for contamination from the laboratory environment, or cross-contamination among an individual patient's specimens. Each PCR amplification was performed with a further negative control containing water instead of any specimen, and a positive control containing $100 \mathrm{fg}$ of $H$ pylori DNA. These controls excluded the possibility of positive reactions being due to contamination of PCR reagents, or negative reactions due to PCR inhibition. The PCR was performed in sterile conditions, with all DNA extraction, PCR setup, and post PCR analysis being done in three separate rooms.

\section{Results}

Fifteen of 23 patients had a Helicobacter associated gastritis on histological examination. Of these, two had contamination during extraction (shown by positive results in their extraction control specimens) and these patient's specimens were discarded (table). Of the remaining 13 patients, 12 had a PCR positive gastric aspirate specimen (fig 3 ) and 5 of them had at least one positive oral specimen.

The eight patients with histologically normal biopsy specimens had no positive oral or gastric aspirate specimens. All had faint PCR positive results for their antral biopsy specimens.

\section{Discussion}

We used a nested PCR in this study rather than a one step PCR. We found that a one step PCR was not sensitive enough for our purposes. It had a good sensitivity for detecting $H$ pylori in gastric biopsy specimens and aspirates, but no oral specimens were found to be positive. A nested PCR not only increases the sensitivity of a PCR reaction but also should increase the specificity of the reaction.

$H$ pylori were shown in the mouths of five of $13(38.5 \%)$ of patients with gastritis. Hammar et al, using a PCR test with a sensitivity of 20 copies of the target gene, detected 


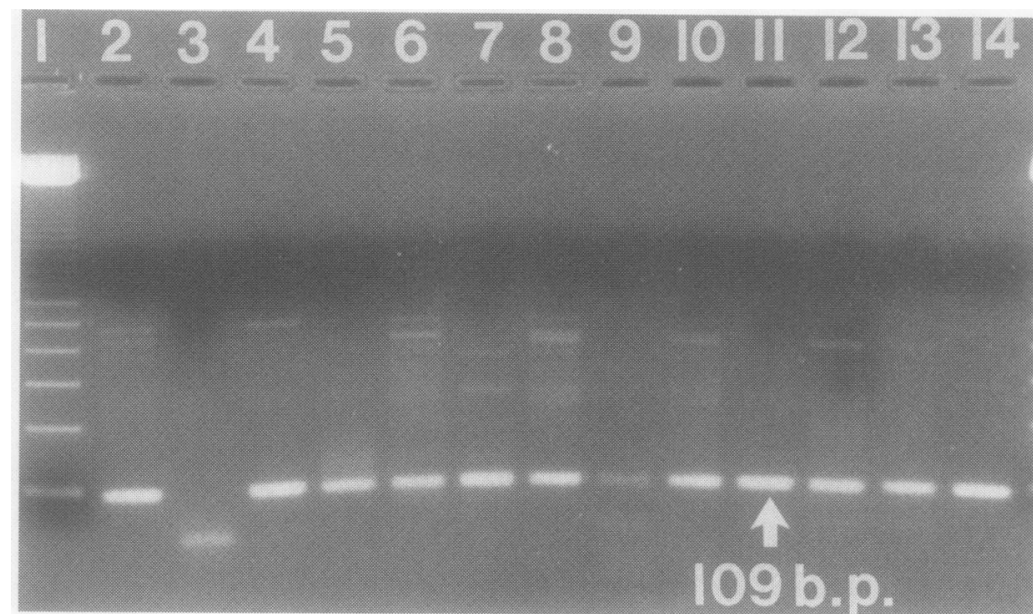

Figure $3 P C R$ gel of gastric aspirates from 13 patients all with Helicobacter gastritis. Lane 1123 base pair ladder; lane 3 negative PCR result; lanes 2 and 4-14 positive PCR results. how they handled their specimens, whether they used all of a specimen or only a section. We digested and extracted the DNA from the whole biopsy specimen. They also do not state their criteria for initial diagnosis of specimens. Hammar et al only report results on patients with histologically confirmed gastritis. ${ }^{8}$

None of these eight patients had any other positive specimens. All of their oral specimens, and all of their gastric aspirates were negative. All of their controls were negative, making contamination of specimens during DNA extraction or PCR preparation very unlikely. One possible explanation for the PCR positive gastric biopsy specimens is that scanty $H$ pylori (perhaps in its coccoid form) are present in normal stomachs. Loffeld et al, using immunohistochemical methods, reported $H$ pylori in the gastric foveolae of $75 \%$ of patients with histologically normal gastric biopsy specimens. ${ }^{12}$ This has not been confirmed by other workers. Alternatively, a nonpathogenic Helicobacter for which we have no specificity data could be present in normal stomachs. This explanation again seems flawed as none of these patients had positive gastric aspirates.

Alternatively, contamination could be occurring at the time of biopsy. The endoscopy equipment is mechanically cleaned and then disinfected using activated $2 \%$ glutaraldehyde. Although disinfection will kill the organism, it will not render the bacterial DNA refractory to amplification with PCR. Indeed, Karim et al reported culturable Helicobacter in one case following routine cleaning (though not disinfection) of biopsy forceps. ${ }^{13}$ All our other specimens were collected with disposable equipment, except for the gastric aspirates, which were collected in sterilised equipment.

In an attempt to confirm this hypothesis, samples were taken from pieces of $H$ pylori negative animal muscle tissue with the same biopsy forceps used in this study, after they had been cleaned and disinfected in the usual way. The samples were treated identically to the gastric biopsy specimens and nested PCRs performed. Of six samples taken in this way, one showed evidence of contamination by $H$ pylor $i$ DNA. All controls were negative. This incidence of contamination from biopsy forceps is less than the incidence of PCR positive specimens seen in the histologically normal antral biopsy specimens, but the samples of muscle were obviously different from antral biopsy specimens, not being covered in mucus. It may be that they were thus less likely to be impregnated by DNA from biopsy forceps.

There has recently been a good deal of speculation on the possible routes of spread of $H$ pylori infection. A high incidence is found among lower socioeconomic groups, ${ }^{14}$ and infection seems to cluster within families. ${ }^{15}$ In one study from Peru the distribution of the disease was associated with an insanitary water supply. ${ }^{16}$ These and other observations have suggested a faecal-oral or found none of 19 normal stomach biop specimens to be positive by PCR. ${ }^{6}$ Their test, however, had a sensitivity of 100 bacterial cells, less than our test. They do not state 
oral-oral route for the spread of this disease. Work on experimental animals has shown that transmission of Helicobacter related organisms occurs in animals with oral contact but not in animals with mainly faecal contamination, such as rats. ${ }^{17}$ This has been taken as evidence for the oral-oral route for infection. The demonstration of the organism in the mouth is corroboration for this hypothesis.

In conclusion, we have shown that our PCR test is a sensitive and specific indicator of $H$ pylori in gastric aspirates and have shown $H$ pylori DNA in the mouths of five out of 13 patients with a Helicobacter associated gastritis. We have also shown that DNA contamination of specimens taken by reusable biopsy forceps can occur even if they are disinfected and washed. This has implications for all researchers using the PCR on specimens collected by this method, whether the site of biopsy be the gastrointestinal or other systems.

This work was supported by the Newby Trust Ltd.

1 Majmudar P, Shah SM, Dhunjibhoy KR, Desai HG. Isolation of Helicobacter pylori from dental plaques in healthy volunteers. Ind $\mathcal{F}$ Gastroenterol 1990;9:271-2.

2 Desai HG, Gill HH, Shankaran K, Mehta PR, Prabhu SR. Dental plaque: a permanent reservoir of Helicobacter pylori? Scand $\mathcal{f}$ Gastroenterol 1991;26: 1205-8.

3 Krajden S, Fuksa M, Anderson J, et al. Examination of human stomach biopsies, saliva, and dental plaque for

4 Patchett S, Beattie S, Leen E, Keane C, O'Morain C. Helicobacter pylori and duodenal ulcer recurrence. $\mathrm{Am}$ f Gastroenterol 1992;87:24-7.
5 Hoshina S, Kahn SM, Jiang W, et al. Direct detection and amplification of Helicobacter pylori ribosomal 16S gene segments from gastric endoscopic biopsies. Diagnost Microbiol Infect Dis 1990;13:473-9.

6 Valentine JL, Arthur RR, Mobley HL, Dick JD. Detection of Helicobacter pylori by using the polymerase chain reaction. F Clin Microbiol 1991;29:689-95.

7 Clayton CL, Kleanthous H, Coates PJ, Morgan DD, Tabaqchali S. Sensitive detection of Helicobacter pylori by using polymerase chain reaction. I Clin Microbiol by using polymerase

8 Hammar M, Tyszkiewicz T, Wadström T, O'Toole PW. Rapid detection of Helicobacter pylori in gastric biopsy material by polymerase chain reaction. $\mathcal{f}$ Clin Microbiol 1992;30:54-8.

9 Foxall PA, Hu L-T, Mobley HLT. Use of polymerase chain reaction-amplified Helicobacter pylori urease structural genes for differentiation of isolates. $\mathcal{F}$ Clin Microbiol 1992;30:729-41.

10 Ho SA, Hoyle JA, Lewis FA, et al. Direct polymerase chain reaction test for detection of Helicobacter pylori
in humans and animals. F Clin Microbiol 1991;29: in humans.

11 Vandamme P, Falsen E, Rossau R, et al. Revision of Campylobacter, Helicobacter, and Wolinella taxonomy: emendation of generic descriptions and proposal of Arcobacter gen. nov. Int $\mathcal{F}$ Syst Bacteriol 1991;41:88-103.

12 Loffeld RJ, Stobberingh E, Flendrig JA, Arends JW. Presence of Helicobacter pylori in patients with nonucler dyspepsia revealing normal antral histological characteristics. Digestion 1990;47:29-34.

13 Karim QN, Rao GG, Taylor M, Baron JH. Routine cleaning and the elimination of Campylobacter pylori from
endoscopic biopsy forceps. F Hosp Infect 1989;13:87-90.

14 Graham DY, Malaty HM, Evans DG, Evans DJ, Klein PD, Adam E. Epidemiology of Helicobacter pylori in an asymptomatic population in the United States. Effect of age, race, and socioeconomic status. Gastroenterology 1991;100:1495-501

15 Drumm B, Perez PG, Blaser MJ, Sherman PM. Intrafamilial clustering of Helicobacter pylori infection. N Eng ₹ Med 1990;322:359-63.

16 Klein PD, Graham DY, Gaillour A, Opekun AR, Smith EO. Water source as risk factor for Helicobacter pylori infection in Peruvian children. Gastrointestinal Physiology Working Group. Lancet 1991;337:1503-6.

17 Lee A, Fox JG, Otto G, Dick EH, Krakowka S Transmission of Helicobacter spp. A challenge to the dogma of faecal-oral spread. Epidemiol Infect 1991;107: 99-109. 